\title{
Polyarticular Juvenile Idiopathic Arthritis, Rheumatoid Factor Positive
}

National Cancer Institute

\section{Source}

National Cancer Institute. Polyarticular Juvenile Idiopathic Arthritis, Rheumatoid Factor

Positive. NCI Thesaurus. Code C119034.

A category of juvenile idiopathic arthritis defined by the presence of arthritis affecting five or more separate joints during the first six months of disease, with positive serologic testing for rheumatoid factor. 